\title{
Transcranial Sonography (TCS) of Brain Parenchyma in Movement Disorders: Quality Standards, Diagnostic Applications and Novel Technologies
}

\section{Transkranielle Sonografie (TCS) des Hirnparenchyms bei Bewegungsstörungen: Qualitätsstandards, diagnostische Anwendungen und neue Technologien}

Authors

Affiliations

\author{
U. Walter ${ }^{1}$, D. Školoudík ${ }^{2}$
}

Department of Neurology, University of Rostock

Department of Neurology, Palacký University Olomouc, Ostrava University and University Hospital Ostrava

\author{
Key words \\ - basal ganglia \\ - brain \\ - ultrasound \\ - movement disorders \\ - TCS
}

\begin{abstract}
received 16.4.2013
\end{abstract}
accepted 22.11.2013

\section{Bibliography \\ Dol http://dx.doi.org/ \\ 10.1055/s-0033-1356415 \\ Published online: April 24, 2014 \\ Ultraschall in Med 2014; 35 : \\ 322-331 ๑ Georg Thieme \\ Verlag KG Stuttgart · New York . ISSN 0172-4614}

\author{
Correspondence \\ Prof. Uwe Walter \\ Department of Neurology, \\ University of Rostock \\ Gehlsheimer Str. 20 \\ 18147 Rostock \\ Germany \\ Tel.: ++49/381/4949696 \\ Fax: ++49/381/4944794 \\ uwe.walter@ \\ med.uni-rostock.de
}

License terms

(c) $(1) \$$

\section{Abstract \\ $\nabla$}

Transcranial B-mode sonography (TCS) of brain parenchyma is being increasingly used as a diagnostic tool in movement disorders. Compared to other neuroimaging modalities such as magnetic resonance imaging (MRI) and computed tomography, TCS can be performed today with portable machines and has the advantages of noninvasiveness and high resistance to movement artifacts. In distinct brain disorders TCS detects abnormalities that cannot be visualized or can only be visualized with significant effort with other imaging methods. In the field of movement disorders, TCS has been established mainly as a tool for the early and differential diagnosis of Parkinson's disease. The postoperative position control of deep brain stimulation electrodes, especially in the subthalamic nucleus, can reliably and safely be performed with TCS. The present update review summarizes the current methodological standards and defines quality criteria of adequate TCS imaging and assessment of diagnostically relevant deep brain structures such as substantia nigra, brainstem raphe, basal ganglia and ventricles. Finally, an overview is given on recent technological advances including TCS-MRI fusion imaging and upcoming technologies of digitized image analysis aiming at a more investigator-independent assessment of deep brain structures on TCS.

\section{Introduction}

$\nabla$

Transcranial B-mode sonography (TCS) of deep brain structures has been established as a tool for the diagnosis and monitoring of degenerative brain

\section{Zusammenfassung \\ $\nabla$}

Die transkranielle B-Bild-Sonografie (TCS) tiefer Hirnstrukturen wird zunehmend als diagnostisches Instrument bei Bewegungsstörungen eingesetzt. Im Vergleich zu anderen Bildgebungsverfahren wie Magnetresonanztomografie (MRT) und Computertomografie liegen die Vorteile der TCS in der hohen Mobilität bis hin zum heute möglichen Einsatz tragbarer Geräte, der gesundheitlichen Unbedenklichkeit und der geringen Störbarkeit durch Patientenbewegungen. Bei bestimmten Hirnerkrankungen detektiert die TCS abnorme Befunde, die mit anderen Verfahren nicht oder nur mit hohem Aufwand darstellbar sind. Im Bereich der Bewegungsstörungen hat sich die TCS hauptsächlich als Instrument zur Früh- und Differenzialdiagnose des idiopathischen Parkinson-Syndroms etabliert. Die postoperative Positionskontrolle von Tiefenhirnstimulations-Sonden, insbesondere im Nucleus subthalamicus, kann zuverlässig und unschädlich mittels TCS durchgeführt werden. Die vorliegende aktuelle Übersicht fasst die gegenwärtigen methodischen Standards zusammen und definiert Qualitätskriterien für eine adäquate Bildgebung und Befundung diagnostisch relevanter tiefer Hirnstrukturen wie Substantia nigra, Hirnstamm-Raphe, Basalganglien und Hirnventrikel. Schließlich wird ein Überblick über aktuelle technologische Entwicklungen inklusive der TCS-MRT-Fusions-Bildgebung und aufkommender Technologien zur digitalen Bildanalyse gegeben, die das Ziel einer geringeren UntersucherAbhängigkeit bei der Beurteilung tiefer Hirnstrukturen mittels TCS verfolgen.

disorders in the past decade [1]. Several years ago, TCS could be recommended only with high-end ultrasound systems (US-S) [1, 2]. Meanwhile, technological advances have enabled standard applications (assessment of the substantia nigra [SN], 
measurement of ventricle widths) with sufficient quality even with a portable US-S [3]. With contemporary high-end US-S, excellent image resolution of deep brain structures is achieved which can be superior to that of magnetic resonance imaging (MRI) under clinical conditions [4]. Compared to MRI and computed tomography, the advances of TCS are its high mobility, short investigation times, non-invasiveness, and low cost. Involuntary head motion in movement disorder patients can be well compensated by the investigator. Most of all, TCS detects abnormalities that are not seen, or only seen with significant effort, with other neuroimaging modalities. The present article gives an overview of the current methodological standard and defines criteria of adequate image quality for diagnostically relevant deep brain structures. In addition, recent technological advances including MRI-TCS fusion imaging and semi-automated visualization techniques are reviewed.

\section{Method \\ $\nabla$}

\section{Equipment}

For TCS an optimized US-S (recommended settings, 0 Table 1 ) equipped with a 2.0- to 3.5-MHz phased-array transducer is used. With it the highest image resolution is achieved at an image depth (distance from the transducer face) of $5-9 \mathrm{~cm}$ which is the socalled focal zone of the transducer [4]. Due to the physical characteristics of ultrasound beams, the image resolution in the axial direction (i.e., along the axis of ultrasound propagation) is about two- to threefold higher than in the lateral direction, usually about $0.7 \times 2 \mathrm{~mm}$. This is the cause of some typical imaging artifacts (e.g. enlargement of small, highly echogenic structures in the lateral direction). Meanwhile, contemporary systems achieve a higher image resolution in the focal zone of up to $0.7 \times 1.1 \mathrm{~mm}$ thanks to intelligent image post-processing technologies [4]. It should be stressed that system-specific image-processing technologies influence distinct measurements such as the assessment of echogenic areas of small brain structures. That is why normal ranges especially for SN echogenic areas need to be obtained separately for each different US-S. The application of tissue harmonic imaging (THI) rather than the conventional imaging mode increases the tissue contrast and can therefore enable an easier delineation of small

Table 1 Recommended ultrasound system settings for TCS.

\begin{tabular}{|c|c|}
\hline parameter & settings \\
\hline \multicolumn{2}{|l|}{ ultrasound machine } \\
\hline image depth & start with $14-16 \mathrm{~cm}$, adapt as needed \\
\hline dynamic range & $45-55 d B$ \\
\hline post-processing function & $\begin{array}{l}\text { moderate suppression of low echogenic } \\
\text { signals }\end{array}$ \\
\hline time gain compensation & $\begin{array}{l}\text { adapt manually as needed or, if available, } \\
\text { apply automated image optimization } \\
\text { (i. e., press the referring button on the } \\
\text { keyboard, standard with contemporary } \\
\text { high-end ultrasound systems) }\end{array}$ \\
\hline image brightness & $\begin{array}{l}\text { adapt manually as needed or, if available, } \\
\text { apply automated image optimization } \\
\text { (i. e., press the referring button on the } \\
\text { keyboard, standard with contemporary } \\
\text { high-end ultrasound systems) }\end{array}$ \\
\hline \multicolumn{2}{|l|}{ Ultrasound transducer } \\
\hline density of crystals / channels & as high as possible, ideally "matrix" probe \\
\hline center frequency of insonation & $2.0-3.5 \mathrm{MHz}$, usually $2.5 \mathrm{MHz}$ \\
\hline
\end{tabular}

echogenic structures, e.g. the SN. THI however largely depends on the quality of the bone window and is not recommended as a standard tool for measurements [2].

\section{Investigation procedures}

The patient is placed in a supine position on an examination chair layer with a variably adjustable lean part. The investigation room should be darkened. The investigator sits behind the patient's head. For the usually performed transtemporal investigation, the TCS transducer is placed on the right temple near the ear and parallel to the orbitomeatal line in order to obtain a standardized axial view of intracranial structures. An important precondition for obtaining valid TCS findings is the identification and keeping of the optimum bone window for insonation. For this, the transducer is moved near the anterior helix of the ear conch to find the position with the best available visualization of brain structures and the contralateral skull bone. Once the optimum position has been found, it is kept by pressing the transducer as well as the small finger/ulnar edge of the hand firmly against the patient's head throughout the whole examination. Even if applying optimum US-S settings ( Table 1 ), assessment of intracranial structures may be not or only partially possible due to an insufficient transtemporal bone window which is found in $5-40 \%$ of patients depending on age, sex and geographic origin [3-6].

- Quality criterion of good image quality: The contralateral skull bone is clearly visualized over its whole extension in the imaging sector.

In neurodegenerative diseases transtemporal TCS is usually carried out on standardized axial imaging planes ( $\bullet$ Fig. 1). For some diagnostic questions TCS is additionally performed on semi-coronal and coronal or transfrontal sagittal imaging planes, e.g. for the assessment of the corpus callosum or the localization of deep brain stimulation (DBS) electrodes [5-7]. TCS findings can be categorized into two types. The first is the semi-quantitative or quantitative assessment of the echogenicity of brainstem structures (SN, red nucleus, midbrain raphe) and basal ganglia (thalamus, lenticular nucleus, head of caudate nucleus), optionally also of the cerebellum and other deep brain structures (e.g. white matter, hippocampal region). The second is the measurement of widths (optionally the cross-sectional area) of the $4^{\text {th }}$ ventricle, $3^{\text {rd }}$ ventricle, frontal horns of lateral ventricles and if needed the cella media.

- Quality criterion of adequate standard of TCS report: The report includes the rating (normal vs. abnormal) and, if obtained, the quantitative measures of echogenicity of SN, red nucleus, midbrain raphe, lenticular nucleus, caudate nucleus (and of other brain structures if investigated) as well as the widths of the $3^{\text {rd }}$ ventricle and frontal horns of lateral ventricles (and of other brain structures if investigated) as well as the final interpretation of TCS findings in response to the diagnostic question.

\section{Midbrain structures \\ $\nabla$}

\section{Visualization and assessment}

For many diagnostic questions in movement disorders, the visualization of midbrain structures (SN, raphe) on an axial imaging plane is of importance.

- Quality criterion of adequate midbrain visualization: The butterfly-shaped midbrain transection surrounded by the highly echogenic basal cisterns (cisterna ambiens, cisterna quadrigemina, cisterna suprasellaris) is completely displayed. 

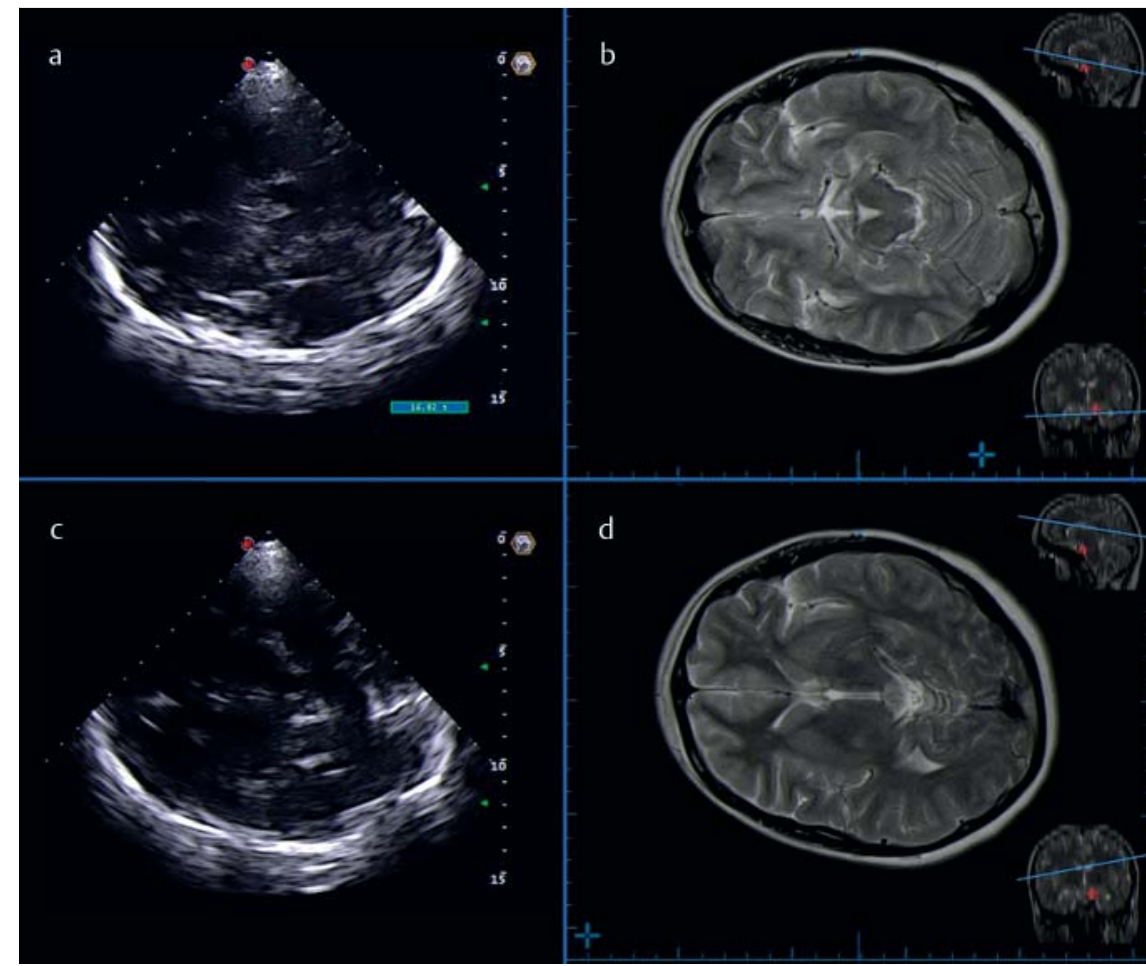

d

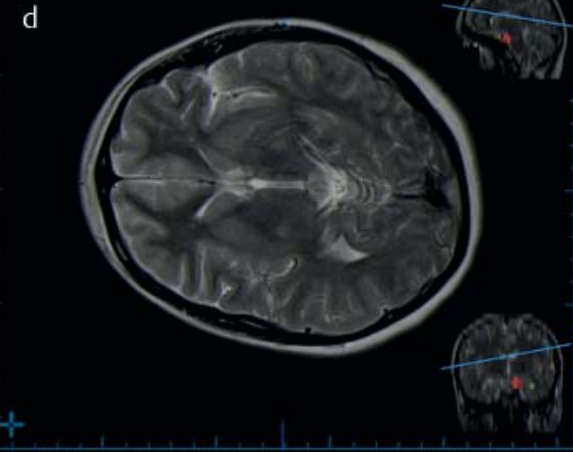

Fig. 1 Standard TCS axial imaging planes in movement disorders. Shown are corresponding TCS and MRI images displayed by an ultrasound system equipped with virtual navigation technology. a TCS image of axial transection through the brain at midbrain level. $\mathbf{b}$ MRI image corresponding to the TCS images shown in a. c TCS image of axial transection through the brain at thalamus level. $\mathbf{d}$ MRI image corresponding to the TCS images shown in $\mathbf{c}$.

Abb. 1 Axiale Standard-Schnittebenen der TCS bei Bewegungsstörungen. Dargestellt sind korrespondierende TCS- und MRT-Aufnahmen, wie sie von einem Ultraschallsystem mit virtueller Navigationstechnologie angezeigt werden. a TCS-Bild der axialen Hirn-Schnittebene auf Höhe des Mittelhirns. b MRT-Bild korrespondierend zum TCS-Bild in a. c TCS-Bild der axialen Hirn-Schnittebene auf Höhe des Thalamus. d MRT-Bild korrespondierend zum TCS-Bild in c.
The SN echosignals may have a patchy, band-like or sometimes wide oval appearance ( $\bullet$ Fig. 2 ). Its appearance may slightly vary even in the same individual if using different transducer angulations or various US-S [8]. This variation is caused by the arched anatomic structure of the SN, the TCS image composition from an about 2-mm thick "slice" of the brain, the 1.5- to 3-fold higher axial than lateral TCS image resolution, and different imaging technologies of diverse US-S $[6,8]$. The best-validated method to grade SN echogenicity is the planimetric measurement of the SN echogenic signals on an axial plane [1, 6, 8-10]. Semiquantitative visual grading is less reliable $[6,10]$. Novel technologies, aiming to reduce investigator dependency, such as measuring the echointensity of the SN relative to the surrounding parenchyma, volumetry, semi-automated SN detection, or complex mathematical echo-signal analysis, have either failed or are not yet ready for clinical application [6, $11-13]$. Because of potential interference with echosignals originating from structures of the basal cisterns, the echogenicity of the SN is assessed only ipsilaterally to insonation. Therefore, SN TCS needs to be performed from both sides. The axial midbrain transection showing the echosignals of the ipsilateral SN in its largest extension is located by slight tilting of the probe. The clearest, most compact view of the SN echogenic signals is located by very slight probe movements. If the SN is seen very clearly, the image is frozen immediately. After choosing the optimum frame using the cine mode if necessary, the midbrain is zoomed out two- to threefold. The SN echogenic signals are surrounded manually by the cursor using the trackball, resulting in automatic calculation of the echogenic area (for video guide see [8]).

- Quality criterion of the adequate visualization of the SN: The echosignals of the SN are displayed at a typical anatomic location in the crus mesencephali and are well separated from the echosignals of the red nucleus and basal cisterns.

The inter-individual variation of SN echogenicity has been suggested to be caused by a variable degree of local iron accumula- tion and abnormal iron-protein compounds but also by gliotic changes $[1,14,15]$. Between the $18^{\text {th }}$ and $75^{\text {th }}$ year of age, the distribution of SN echogenicity can be regarded as nearly constant $[16,17]$, even though there are reports of a moderate increase during adult life decades [18], especially after the age of 80 [19]. To rate SN echogenicity in an individual as normal or increased ("hyperechogenic"), the $75^{\text {th }}$ and $90^{\text {th }}$ percentile of measures in the normal population are used as a reference [1], and the larger of bilaterally measured SN echogenic sizes is used for classification as follows:

- normal echogenic: measured area is below the $75^{\text {th }}$ percentile - moderately hyperechogenic: measured area is between the $75^{\text {th }}$ and the $90^{\text {th }}$ percentile

- markedly hyperechogenic: measured area is above the $90^{\text {th }}$ percentile.

The normal ranges need to be established for each different US-S and because of some potential investigator dependency also for each different lab. For this, at least 50 healthy adults should be investigated bilaterally. Table 2 summarizes the cut-off values published so far for various US-S [3, 10, 16 - 18, 20 - 25].

The evaluation of the midbrain raphe is more demanding due to a higher variability of its sonographic appearance depending on the US-S quality and settings ( $\bullet$ Table 1 ). Moreover, the assessment of the raphe is anatomically restricted to the lower midbrain with obligatory simultaneous visualization of the red nucleus. While in early reports 4 grades of echogenicity were applied (1: raphe not visible; 2 : reduced or interrupted echogenicity; 3 : normal, i. e. continuous line with an echogenicity similar to that of red nucleus, 4: increased echogenicity) [26], a current consensus guideline recommends the discrimination of only of two grades (normal vs. reduced echogenicity) ( $\bullet$ Fig. 2) [2]. Raphe echogenicity should only be classified as reduced if TCS from both sides shows reduced echogenicity under adequate imaging conditions. 


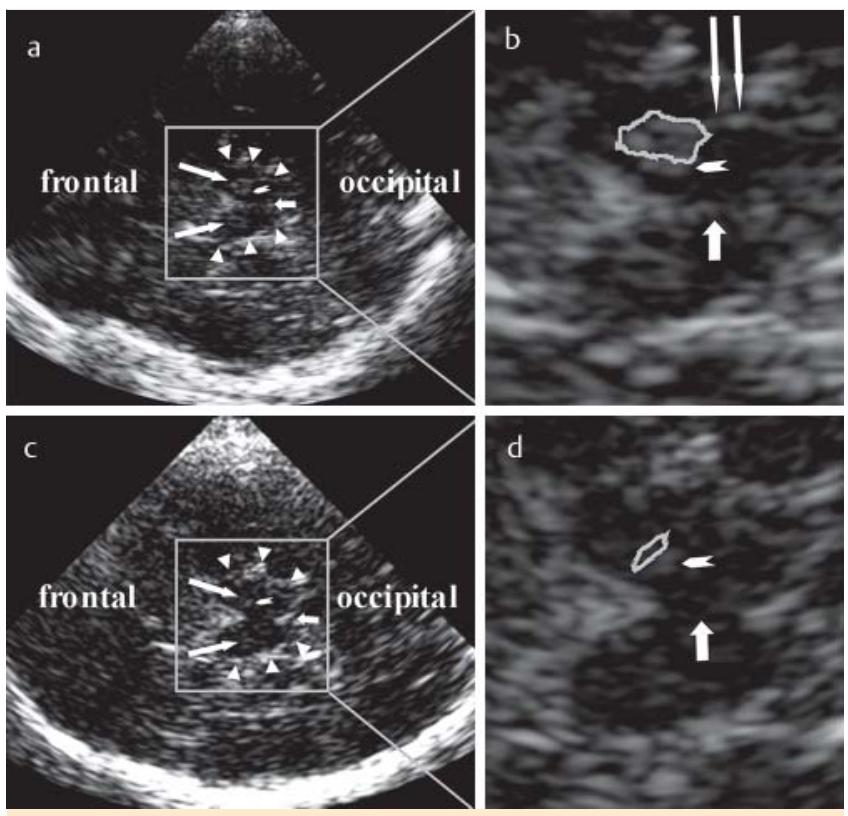

Fig. 2 TCS findings at axial midbrain transection. a In the center of the image, the butterfly-shaped, weakly echogenic midbrain is displayed which is surrounded by the highly echogenic basal cisterns (indicated by triangles). This individual exhibits a bilaterally enlarged echogenic area of substantia nigra (SN hyperechogenicity, long arrows). The lateral echosignal of ipsilateral red nucleus (arrow head) here is in conjunction with the echosignals of the SN. The short arrow indicates the typically highly echogenic aqueduct. b TCS image of the midbrain after zooming the image shown in a; in this panel, the echosignals of the SN are surrounded (here: enlarged echogenic area; arrow head: red nucleus; arrow: normal echogenic raphe). Note the imaging artifact originating from the basal cistern at typical position (long arrows) that should not be mistaken for SN echosignals. c TCS images of a subject with normal echogenic SN (long arrows; short arrow: aqueduct; arrow head: ipsilateral red nucleus) but a reduced echogenicity of midbrain raphe. $\mathbf{d}$ TCS image of the midbrain after zooming the image shown in c; in this panel, the echosignals of the SN are surrounded (here: normal echogenic area). Note the reduced echogenicity of midbrain raphe which is invisible in this example (arrow; arrow head: red nucleus).

Abb.2 Typische TCS-Befunde in der axialen Mittelhirnebene. a Im Bildzentrum zeigt sich der schmetterlingsförmige Querschnitt durch das schwach echogene Mittelhirn, welches von den stark echogenen basalen Zisternen umrandet ist (Dreiecke). Bei diesem Individuum zeigt sich ein beidseits vergrößertes echogenes Areal der Substantia nigra (SN-Hyperechogenität, lange Pfeile). Das laterale Randecho des Nucleus ruber (Pfeilspitze) ist hier mit den Echosignalen der Substanta nigra verschmolzen. Der kurze Pfeil zeigt auf den typischerweise kräftig echogenen Aquädukt. b Vergrößerter Bildausschnitt des Mittelhirns aus a; die Echosignale der SN wurden umrandet (hier: vergrößerte echogene Fläche; Pfeilspitze: Nucleus ruber; Pfeil: normal echogene Raphe). Der von der basalen Zisterne an typischer Position ausgehende Bildgebungsartefakt (lange Pfeile) sollte nicht mit den Echosignalen der SN verwechselt werden. c TCS-Bild bei einem Individuum mit normal echogener SN (lange Pfeile; kurzer Pfeil: Aquädukt; Pfeilspitze: ipsilateraler Nucleus ruber), aber reduzierter Echogenität der Mittelhirn-Raphe. d Vergrößerter Bildausschnitt des Mittelhirns aus c; die Echosignale der SN wurden umrandet (hier: normale echogene Fläche). Beachte die reduzierte Echogenität der Mittelhirn-Raphe, die in diesem Fall „unsichtbar“ ist (Pfeil; Pfeilspitze: Nucleus ruber).

- Quality criterion of adequate assessability of the midbrain raphe: Basal cisterns, aqueduct and red nucleus are clearly displayed.

The red nucleus, located in the caudal midbrain between the raphe und SN, is typically visualized as two small stripe-like echosignals at its medial and lateral border, respectively. Sometimes its lateral echosignal cannot be discriminated from the echosignals of the SN but, if so, this usually does not relevantly interfere with measurements of the SN echogenic area. Occasionally a healthy subject exhibits marked echogenicity of the red nucleus in its full anatomical extension. This finding is rated as a hyperechogenicity even though the diagnostic meaning is unclear.

- Quality criterion of adequate assessability of the red nucleus:

Basal cisterns, SN and midline structures (raphe, aqueduct) are clearly displayed.

\section{Diagnostic relevance}

SN hyperechogenicity is characteristically found in more than $90 \%$ of Parkinson's disease (PD) patients, does not remarkably change in the disease course and is unrelated to PD severity [1]. Marked SN hyperechogenicity is also found in about $10 \%$ of healthy adults and has been associated in them with a (subclinical) malfunction of the nigrostriatal dopaminergic system $[1,16]$. In a 5-year follow-up study performed in Southern Germany and Austria of 1800 subjects at ages between 50 and 70 years without PD at baseline, SN hyperechogenicity was associated with a 20 -fold increased risk of developing PD [27]. However, the predictive value of this TCS finding alone is low since more than $80 \%$ of healthy subjects with SN hyperechogenicity will never develop PD during their lifetime [28]. Moreover, SN hyperechogenicity has been found with variable frequencies in a number of other neurodegenerative diseases [28]. Still, SN TCS is helpful for the discrimination of PD from essential tremor [21, 29]. For the differentiation of PD from atypical Parkinsonian syndromes, SN TCS should be combined with TCS of other brain structures ( $\triangle$ Table 3), or with distinct clinical findings [1, 30-33]. The combined presence of normal SN echogenicity and lenticular nucleus hyperechogenicity clearly discriminates atypical Parkinsonian syndromes from idiopathic PD [30, 31]. In turn, the triad of SN hyperechogenicity, motor asymmetry and hyposmia is highly predictive for PD already at very early disease stages [32]. The results of several studies underpin the idea that risk scores comprising the finding of SN hyperechogenicity and other risk markers may be valuable in the prediction of subsequent PD [27, 32, 33]. The recently issued recommendations of the European Federation of Neurological Societies and the European Section of the Movement Disorder Society for the diagnosis of PD state that TCS is recommended (Level A) for: (I) the differential diagnosis of PD from atypical Parkinsonian syndromes and secondary Parkinsonian syndromes, (II) the early diagnosis of PD and (III) the detection of subjects at risk for PD [33].

A reduced SN echogenicity (hypoechogenicity) has been demonstrated in patients with idiopathic restless legs syndrome $[34,35]$. SN hypoechogenicity has been proposed to be present at a sum value $\leq 0.20 \mathrm{~cm}^{2}$ of bilaterally measured SN echogenic areas [35]. Its diagnostic value, however, remains to be established.

The SN represents an important landmark structure for the sonographic assessment of DBS electrode position in PD patients with DBS of the subthalamic nucleus. Optimum DBS electrode position in the subthalamic nucleus can be diagnosed on TCS if in the axial or slightly semi-axial sonogram of the midbrain the virtual tip of DBS electrode touches or "dives within" the echosignals of the SN which are usually hyperechogenic and therefore easily recognizable in PD patients ( $\bullet$ Fig. 3 d) [7].

A reduced echogenicity of the midbrain raphe has been detected in about $10 \%$ of the normal population but in $50-70 \%$ of patients with depressive disorders, and is discussed to reflect an altera- 


\begin{tabular}{|c|c|c|c|c|}
\hline \multirow{2}{*}{$\begin{array}{l}\text { manufacturer/ ultrasound } \\
\text { system }\end{array}$} & \multirow{2}{*}{$\begin{array}{l}\text { probe/ frequency } \\
{[\mathrm{MHz}]}\end{array}$} & \multicolumn{2}{|c|}{ cut-off value $\left[\mathrm{cm}^{2}\right]$} & \multirow[t]{2}{*}{ references } \\
\hline & & SN-h ${ }^{1}$ & Marked SN-h ${ }^{1}$ & \\
\hline Aloka/Prosound Alpha 10 & UST-52 105/2.5 & $\geq 0.19$ & $\geq 0.25$ & Mijajlović et al. [20] \\
\hline Esaote/MyLab25 Gold & $\mathrm{PA} 240 / 2.5$ & $\geq 0.20$ & $\geq 0.25$ & Go et al. [3] \\
\hline Esaote/MyLab Twice & PA240/2.5 & $\geq 0.24$ & $\geq 0.30$ & (own data) \\
\hline General Electric/Logiq 7 & $3 S / 2.5$ & & $\geq 0.24$ & Stockner et al. [21] \\
\hline General Electric/Logiq 9 & $3 S / 2.5$ & $\geq 0.20$ & & Fedotova et al. [22] \\
\hline Philips/HDI 5000 SonoCT & $P 2-4 / 2.5$ & $\geq 0.20$ & & Kim et al. [23] \\
\hline Philips/HP Sonos 5500 & $S 4 / 2.0-2.5$ & $\geq 0.20$ & $\geq 0.27$ & $\begin{array}{l}\text { Mehnert et al. [17] } \\
\text { Hagenah et al. [18] }\end{array}$ \\
\hline Siemens/Acuson Antares & PX4-1/2.5 & $\geq 0.24$ & $\geq 0.30$ & $\begin{array}{l}\text { Van de Loo et al. [10] } \\
\text { Glaser et al. [24] }\end{array}$ \\
\hline Siemens/Sonoline Elegra & 2.5PL20/2.6 & $\geq 0.20$ & $\geq 0.25$ & Berg et al. [16] \\
\hline Toshiba Aplio XG & PST-20CT/2.5 & $\geq 0.16$ & $\geq 0.22$ & Vivo-Orti et al. [25] \\
\hline
\end{tabular}

Table 2 Reported cut-off values for the discrimination between normal echogenicity and hyperechogenicity of substantia nigra with different contemporary ultrasound systems.
Table 3 Typical TCS findings in normal subjects aged $>50$ years and in patients with various movement disorders with a disease duration of $<5$ years.

\begin{tabular}{llll} 
syndrome & $\begin{array}{l}\text { hyperechogeni- } \\
\text { city of Substan- } \\
\text { tia nigra }\end{array}$ & $\begin{array}{l}\text { hyperechogeni- } \\
\text { city of Lenticular } \\
\text { nucleus }\end{array}$ & $\begin{array}{l}\text { dilatation of } \\
3^{\text {rd }} \text { ventricle } \\
>10 ~ \mathbf{~ m m}\end{array}$ \\
\hline normal (age > 50y) & $(+)$ & + & $(+)$ \\
\hline Parkinson's disease & +++ & + & $(+)$ \\
\hline Essential tremor & + & + & $(+)$ \\
\hline MSA-P & $(+)$ & +++ & + \\
\hline PSP-RS & ++ & +++ & ++ \\
\hline Corticobasal & +++ & +++ & - \\
degeneration & & ++ & + \\
\hline $\begin{array}{l}\text { Dementia with } \\
\text { Lewy bodies }\end{array}$ & +++ & & + \\
\hline Wilson's disease & ++ & ++ & $(+)$ \\
\hline Idiopathic dystonia & $(+)$ & +++ & + \\
\hline Huntington's disease & ++ & ++1 & ++ \\
\hline
\end{tabular}

MSA-P = multiple-system atrophy, parkinsonian type; PSP-RS = progressive supranuc lear palsy, Richardson syndrome. If a brain structure is assessed bilaterally, the most abnormal finding is used for classification of a patient. The symbols indicate the frequency of abnormal TCS findings in the patients investigated in our labs: $-=$ found in no case; $(+)=$ rarely found $(<10 \%) ;+=$ occasionally found $(10-20 \%) ;++=$ frequently found $(30-50 \%) ;+++=$ very frequently found $(>80 \%)$.

${ }^{1}$ Hyperechogenicity also of the caudate nucleus is very frequently found in HD patients.

tion of the central serotonergic system [26, 36]. Also PD and Huntington's disease patients with associated depression often exhibit this TCS feature [36-38]. The histopathological correlates and the predictive value of this finding remain to be elucidated.

\section{Cerebellum and $4^{\text {th }}$ ventricle \\ $\nabla$}

Visualization and assessment

To approach the cerebellar imaging plane one should start at the axial midbrain plane. Then the transducer is twisted by about $45^{\circ}$ in a semi-coronal position, with cranial movement of the anterior part of the transducer and caudal movement of the posterior part. Eventually a slight tilting of the transducer is necessary to find the optimum plane which is characterized by simultaneous display of the midbrain and thalami ( $\bullet$ Fig. 4a). On this plane the $4^{\text {th }}$ ventricle can be seen in dorsal vicinity to the midbrain. In children and young adults the $4^{\text {th }}$ ventricle often cannot be recognized due to its tightness [39]. However, in elderly subjects and particularly in patients with cerebellar atrophy it is usually visible. Mild cerebellar atrophy corresponds to a comma-shaped appearance, and pronounced atrophy to an oval appearance of the $4^{\text {th }}$ ventricle.

- Quality criterion of adequate assessability of the $4^{\text {th }}$ ventricle and dentate nucleus: Bilateral thalami, midbrain (= reference structure), the lateral borders of the $4^{\text {th }}$ ventricle and central parts of the cerebellum are clearly displayed.

There is currently no standard for the assessment of the cerebellum. Reported abnormal findings are $4^{\text {th }}$ ventricle dilatation, a coarse appearance of the cerebellar sulci, and increased echogenicity of the dentate nuclei $[39,40]$. Fourth-ventricle measures are the width and cross-sectional area on a semi-coronal plane. A cross-sectional area $>0.6 \mathrm{~cm}^{2}$ can be regarded as abnormal.

\section{Diagnostic relevance}

Abnormal TCS findings of the $4^{\text {th }}$ ventricle and cerebellum have been demonstrated in patients with various forms of hereditary spinocerebellar ataxia (Friedreich's ataxia, SCA-3, SCA-17) [39, 40]. So far there are no reports showing a diagnostic specificity of abnormal cerebellum TCS findings, neither alone nor in combination with other TCS findings.

\section{Basal ganglia and ventricles}

\section{Visualization and assessment}

The second standard imaging plane in the assessment of movement disorders is the axial basal ganglia plane (thalamus plane). This plane is approached, if starting from the axial midbrain plane, by tilting the transducer about $20^{\circ}$ upwards ( $\bullet$ Fig. 1 ). In the case of a narrow transtemporal bone window, the transducer should be slightly shifted caudally - simultaneously with the upward tilting maneuver - in order to keep the bone window. Even if the bone window is poor, the pineal gland is mostly visible due 


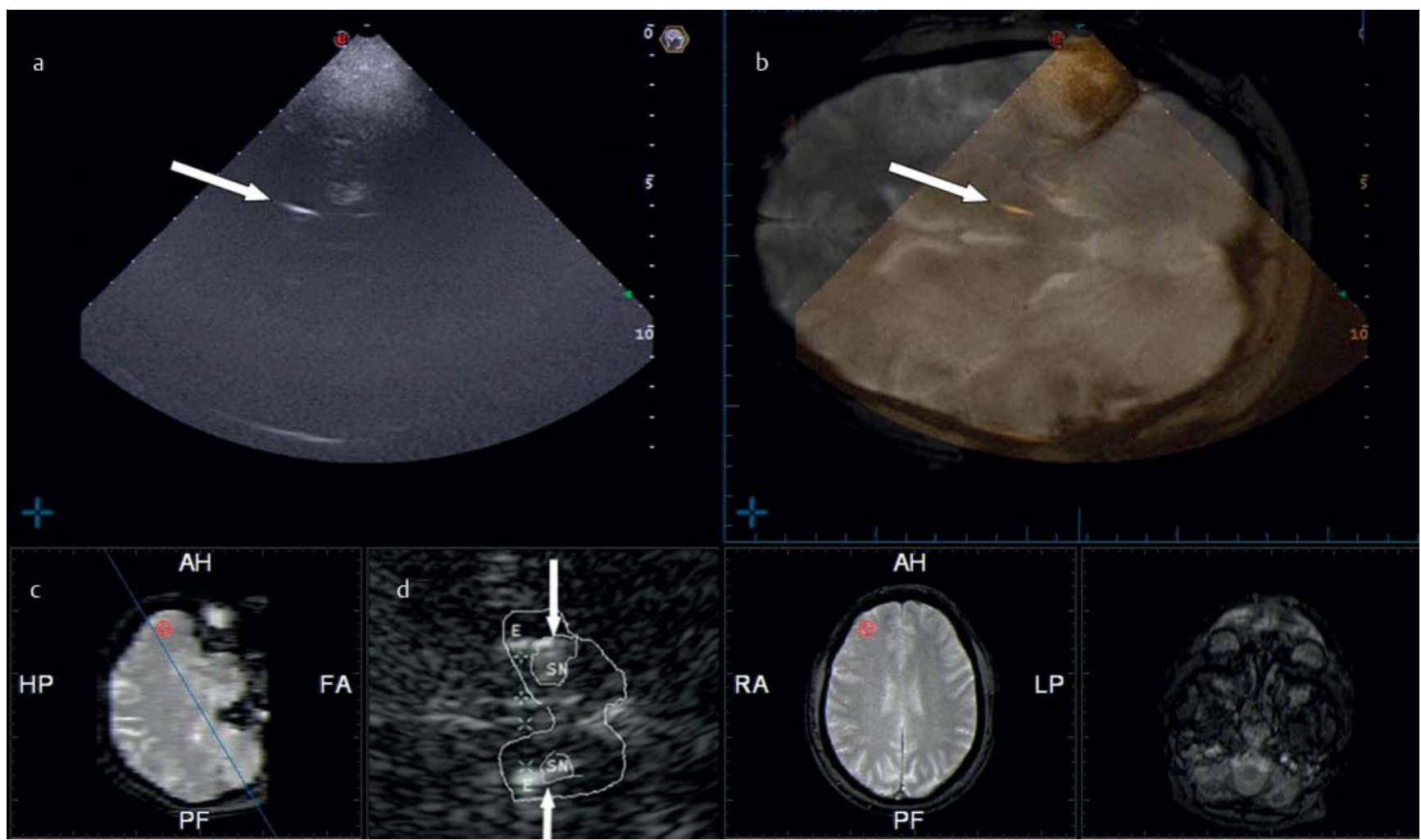

Fig. 3 Imaging of deep brain stimulation (DBS) electrodes on TCS. Shown are corresponding TCS and MRI images displayed by an ultrasound system equipped with virtual navigation and fusion imaging technology. a TCS image of semi-coronal transection through the brain of a patient with DBS of subthalamic nucleus. The image brightness was reduced to clearly display the DBS electrode (arrow) without reverberation artifacts. b MRI image fused with the TCS image shown in a. The DBS electrode (arrow) depicted on the TCS images projects with its tip in the subthalamic nucleus on the corresponding (pre-operatively obtained) MR image. c Panel showing the angle of the semi-coronal imaging plane applied in a, b. $\mathbf{d}$ Semi-coronal zoomed TCS image of the midbrain (normal image brightness; $\mathrm{SN}=$ substantia nigra; $E=D B S$ electrode). The arrows indicate the virtual tips of the bilateral DBS electrodes which "dive" in the echosignals of the substantia nigra.

to its calcification which therefore represents an important landmark structure of this plane. The reference structures of the axial basal ganglia plane are the bilateral, weakly echogenic thalami and the $3^{\text {rd }}$ ventricle which appears as a highly echogenic double line between the thalami ( $\bullet$ Fig. 4b). Near to the midline in a more frontal position, the frontal horns of lateral ventricles are displayed. Sometimes it is necessary to tilt the transducer slightly in a frontal direction for visualization.

- Quality criterion of the adequate display of the axial basal ganglia plane: Pineal gland (usually highly echogenic due to calcification), bilateral thalami (= reference structure), $3^{\text {rd }}$ ventricle and contralateral frontal horn are clearly visible.

On this imaging plane the widths of the $3^{\text {rd }}$ ventricle and contralateral frontal horn are measured. So far there is no consensus guideline on the location at which these measures should be obtained. While in early reports the maximum width of the $3^{\text {rd }}$ ventricle was measured, most groups meanwhile prefer measuring the minimum width [2]. The width of the contralateral frontal horn is measured, as a standard in our labs, at the most frontal position at which the bilateral frontal horns are in junction
Abb.3 Darstellung von Tiefenhirnstimulations- (THS-) Elektroden mittels TCS. Dargestellt sind korrespondierende TCS- und MRT-Aufnahmen, wie sie von einem Ultraschallsystem mit virtueller Navigations- und Bildfusionstechnologie angezeigt werden. a Semi-koronares TCS-Schnittbild durch das Gehirn eines Patienten mit THS im Nucleus subthalamicus. Die Bildhelligkeit wurde reduziert, um die THS-Elektrode (Pfeil) möglichst klar und ohne Reverberations-Artefakte darzustellen. b Fusion von MRT-Bild und korrespondierendem TCS-Bild aus a. Die THS-Elektrode (Pfeil), die sich im TCS-Bild deutlich zeigt, projiziert mit ihrer Spitze in den Nucleus subthalamicus auf dem korrespondierenden (präoperativ erstellten) MRT-Bild. c Darstellung des Winkels der semi-koronaren Schnittebene in a, b. d Semi-koronares, vergrößertes TCS-Bild des Mittelhirns (normale Bildhelligkeit; SN = Substantia nigra; $\mathrm{E}=$ THS-Elektrode). Die Pfeile zeigen die virtuellen Spitzen der beidseitigen THS-Elektroden, welche in die Echosignale der Substantia nigra „eintauchen“.

$(\bullet$ Fig. 4b). The measurement points are placed in a way that their conjunction line is parallel to the mid-axis of the imaging sector. Normal ranges of ventricle widths are age-dependent. In subjects under/over the age of 60 , widths of $>7 />10 \mathrm{~mm}$ ( $3^{\text {rd }}$ ventricle) and $>17 />20 \mathrm{~mm}$ (frontal horn) are regarded as abnormal [2].

If the contralateral thalamus and the contralateral frontal horn are clearly visible, the location of the (contralateral) lenticular nucleus and caudate nucleus can be inferred from their expected anatomical position, as these basal ganglia usually are not discernible from the surrounding white matter. Increased echogenicity, on visual assessment, of basal ganglia compared to the surrounding white matter is regarded as abnormal ("hyperechogenicity") ( $\bullet$ Fig. 5). Hyperechogenicity of the lenticular or caudate nucleus usually appears in a circumscribed area rather than as a diffuse change of the referring nucleus. It is important to distinguish other structures that can cause misdiagnosis of basal-ganglia hyperechogenicity due to lateral imaging artifacts. These are mainly the highly echogenic borders of the lateral ventricles, and more caudally the basal cisterns. Moreover, especially 

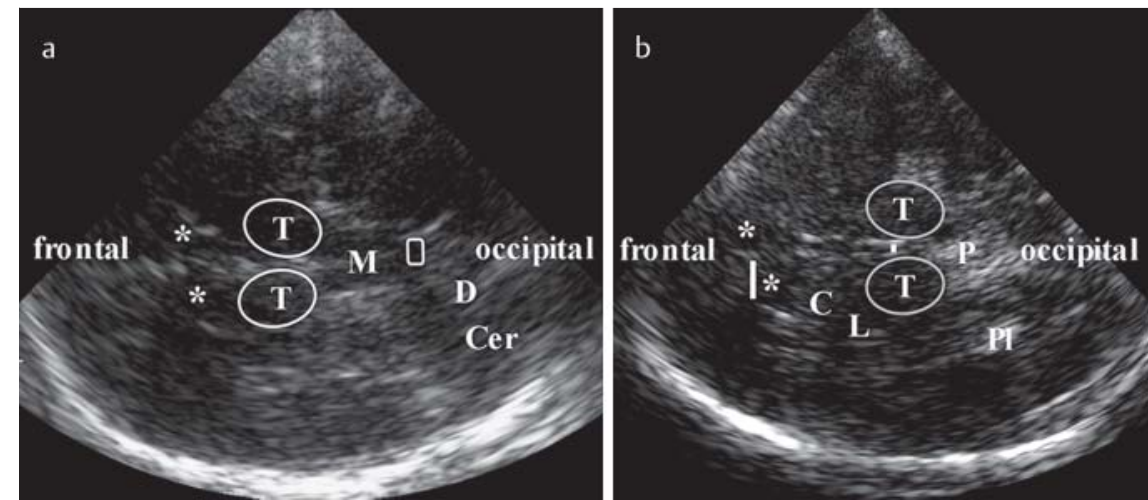

Fig. 4 Further standard imaging planes on TCS. a Cerebellar imaging plane with measurement of the 4 th ventricle (rectangle). Cer $=$ cerebellum, $\mathrm{D}=$ dentate nucleus, $\mathrm{M}=$ midbrain, $\mathrm{T}=$ thalamus, ${ }^{*}=$ frontal horn of lateral ventricle. $\mathbf{b}$ Basal-ganglia imaging plane with measurement of the 3rd ventricle (short bar) and the contralateral frontal horn (long bar). Lenticular and caudate nuclei normally are isoechogenic to surrounding brain parenchyma. $\mathrm{C}=$ caudate nucleus, $\mathrm{L}=$ lenticular nucleus, $\mathrm{P}=$ pineal gland, $\mathrm{Pl}=$ choroid plexus in the dorsal horn of lateral ventricle, $\mathrm{T}=$ thalamus, ${ }^{*}=$ frontal horn of lateral ventricle.
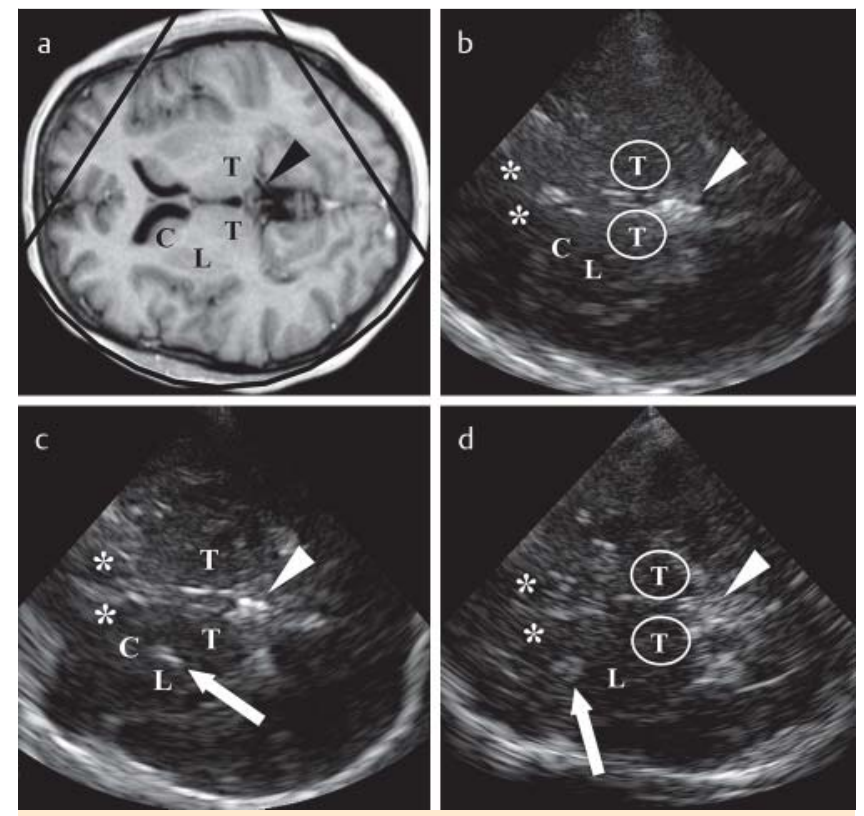

Fig. 5 TCS findings of basal ganglia. $C=$ caudate nucleus, $L=$ lenticular nucleus, $\mathrm{T}=$ thalamus, ${ }^{*}=$ frontal horn of lateral ventricle. The triangle indicates pineal gland (highly echogenic on TCS). a The MR image corresponds to the sonograms in $\mathbf{b}-\mathbf{d}$. $\mathbf{b}$ Normal echogenicity of basal ganglia, including the lenticular nucleus. $\mathbf{c}$ Hyperechogenicity of the lenticular nucleus (arrow). $\mathbf{d}$ Hyperechogenicity of the caudate nucleus (arrow).

Abb. 5 Basalganglien-Befunde der TCS. C = Nucleus caudatus, L= Nucleus lentiformis, $\mathrm{T}=$ Thalamus, ${ }^{*}=$ Seitenventrikel-Vorderhorn. Das Dreieck zeigt auf die Glandula pinealis (kräftig echogen in der TCS). a MR-Tomogramm korrespondierend zu den Sonogrammen in b-d. b Normale Echogenität der Basalganglien einschließlich des Nucleus lentiformis. c Hyperechogenität des Nucleus lentiformis (Pfeil). d Hyperechogenität des Nucleus caudatus (Pfeil).

in patients with very good bone windows, reverberation artifacts originating from the highly echogenic ventricular structures (borders, choroid plexus) may mimic basal-ganglia hyperecho-
Abb. 4 Weitere Standard-Schnittebenen der TCS. a Darstellung der Kleinhirnebene zur Messung des 4 . Ventrikels (Rechteck). Cer = Cerebellum, $\mathrm{D}=$ Nucleus dentatus, $\mathrm{M}=$ Mittelhirn, $\mathrm{T}=$ Thalamus, ${ }^{*}=$ Seitenventrikel-Vorderhorn. b Darstellung der Basalganglienebene zur Messung des 3. Ventrikels (kurzer Balken) und des kontralateralen Seitenventrikel-Vorderhornes (langer Balken). Nucleus lentiformis und Nucleus caudatus unterscheiden sich in ihrer Echogenität nicht vom subkortikalen Marklager. $C=$ Nucleus caudatus, $\mathrm{L}=$ Nucleus lentiformis, $\mathrm{P}=\mathrm{Glandula}$ pinealis, $\mathrm{Pl}=$ Plexus choroideus im Seitenventrikel-Hinterhorn, $\mathrm{T}=$ Thalamus, ${ }^{*}=$ Seitenventrikel-Vorderhorn.

genicity. To avoid such misdiagnosis, it is indispensable to gain certainty about the anatomical relationship between the basal ganglia and neighboring structures potentially causing apparent hyperechogenicity by slightly tilting and twisting the transducer. Most groups assess the basal ganglia contralateral to the side of insonation (unlike SN) since the contralateral structures are displayed in a larger area in the sector-shape sonogram [2]. On the other hand, some authors prefer ipsilateral assessment of basal ganglia since they are ipsilaterally more in the focal zone of the transducer and are therefore displayed with higher image resolution. In our experience assessment of contralateral basal ganglia can be reliably performed with most US-S. However, because of higher image resolution in the focal zone, we prefer assessment of the DBS electrode position in the basal ganglia (globus pallidus internus, thalamus) ipsilaterally to the side of insonation [7]. The diagnosis of basal-ganglia hyperechogenicity is usually made visually [2]. In addition, hyperechogenic areas may be measured planimetrically, similar to measurements of SN hyperechogenicity $[2,41]$. Recently, the echo-intensity of basal ganglia was reliably quantified using digitized image analysis [12, 42].

- Quality criterion of adequate assessability of the contralateral lenticular nucleus and caudate nucleus: Contralateral thalamus, $3^{\text {rd }}$ ventricle, frontal of lateral ventricle, and subcortical white matter (= reference structure) are clearly displayed.

\section{Diagnostic relevance}

Increasing width of the $3^{\text {rd }}$ ventricle and frontal horns correlates with the degree of cognitive impairment in the normal population [43]. A pronounced dilatation of all ventricles is an instant diagnosis on TCS and indicates the presence of hydrocephalus or advanced brain atrophy [1]. Third-ventricle dilatation typically found already at early stages of progressive supranuclear palsy (Richardson syndrome) supports its discrimination from PD [31]. Hyperechogenicity of the lenticular nucleus is a characteristic finding in patients with generalized, segmental, focal and taskrelated forms of idiopathic dystonia [41, 42]. However, the specificity of this TCS finding has been challenged by one study [44], and further studies are needed to assess its diagnostic value, e.g. 
for the discrimination of idiopathic dystonia from psychogenic movement disorders. Lenticular nucleus hyperechogenicity is frequently detected in brain disorders with an accumulation of iron, manganese, or copper, e.g. in Wilson's disease [14]. This finding is also present in $70-90 \%$ of patients with atypical Parkinsonian syndromes and supports, especially if combined with other TCS findings ( $\bullet$ Table 3 ), their discrimination from PD $[1,30,31]$. Caudate nucleus hyperechogenicity is often found in patients with Huntington's disease [38] and may support discrimination from other chorea disorders [unpublished data]. A pronounced hyperechogenicity of basal ganglia, with brightness similar to that of the pineal gland and calcified structures of the choroid plexus in the dorsal horn of the lateral ventricle, indicate calcification of the basal ganglia and may be seen as a dot-like lesion in elderly subjects but is more extended in Fahr's disease $[1,45]$.

\section{Novel technologies \\ $\nabla$}

The reliability of TCS assessment of small deep brain structures such as the SN mainly depends on two factors: (1) the investigator's experience and skill, which is associated with a potential subjective bias, and (2) the quality of the bone window [1-6, $8-10$ ]. The influence of the latter may be reduced only slightly by lowering the insonation frequency, usually to $1.8-2.0 \mathrm{MHz}$, in the case of poor bone windows. However, the influence of the investigator dependency could potentially be overcome by applying optimized techniques for automated structure detection and digitized image analysis. Several approaches for automated SN detection and the quantification of its echogenicity have been published recently, including principal component analysisbased artificial neural networks [46], active contour segmentation algorithms [47], invariant scale blob detection [13], and 3-dimensional SN detection (volumetry) based on random forests [48]. Still, the performance of these off-line image analysis tech- nologies is largely influenced by the quality of the TCS image primarily obtained by the investigator. So it was important to integrate a test for sufficient image quality into such software as a prerequisite for diagnostic application in the clinical routine [12]. In first clinical studies employing such a digitized image analysis tool for 2-dimensional TCS images [12], the elliptical marker highlighting the region of interest (ROI) was manually placed in the target area (SN, lenticular nucleus) [42, 49]. After the placement of the ROI in the target area within the TCS image, the algorithm computes the area for each grayscale intensity $I$ (from 0 to 255) inside the ROI area (here, size of ROI area $A=50 \mathrm{~mm}^{2}$ ) ( $\bullet$ Fig. 6 ). In a pilot study using this novel software [12], the automatically measured SN echogenic areas in the normal population were similar across different US-S (e.g., Esaote MyLabTwice and GE Vivid 7 Pro; r=0.996) [49]. Moreover, manual measures of SN echogenic area obtained by highly experienced investigators correlated well with measures of digitized analysis (correlation coefficients ranging from 0.79 to 0.81 ) [49], as did lenticular nucleus measures $(r=0.74)$ [42]. The sensitivity and specificity for the diagnosis of PD based on the detection of SN hyperechogenicity by digitized image analysis were $87 \%$ and $92 \%$, respectively [49]. In another study applying 3-dimensional quantification of SN echogenicity (volumetry), a sensitivity and specificity for the diagnosis of PD of up to $91 \%$ and $73 \%$ were reported [11].

Nevertheless, the accuracy of digitized image analysis-based TCS diagnostics still depends on the investigators ability to identify and focus on the best available TCS image for visualization of a specific brain structure. Novel technologies enabling the realtime image fusion of TCS with MRI, CT or PET images, previously obtained and imported into the US-S, promise a further reduction of investigator dependency of TCS. Meanwhile, several manufacturers are marketing virtual navigation and fusion imaging applications embedded in their high-end US-S. To enable the virtual navigation on TCS-MRI fusion images, the position and orientation of the ultrasound transducer are continuously tracked

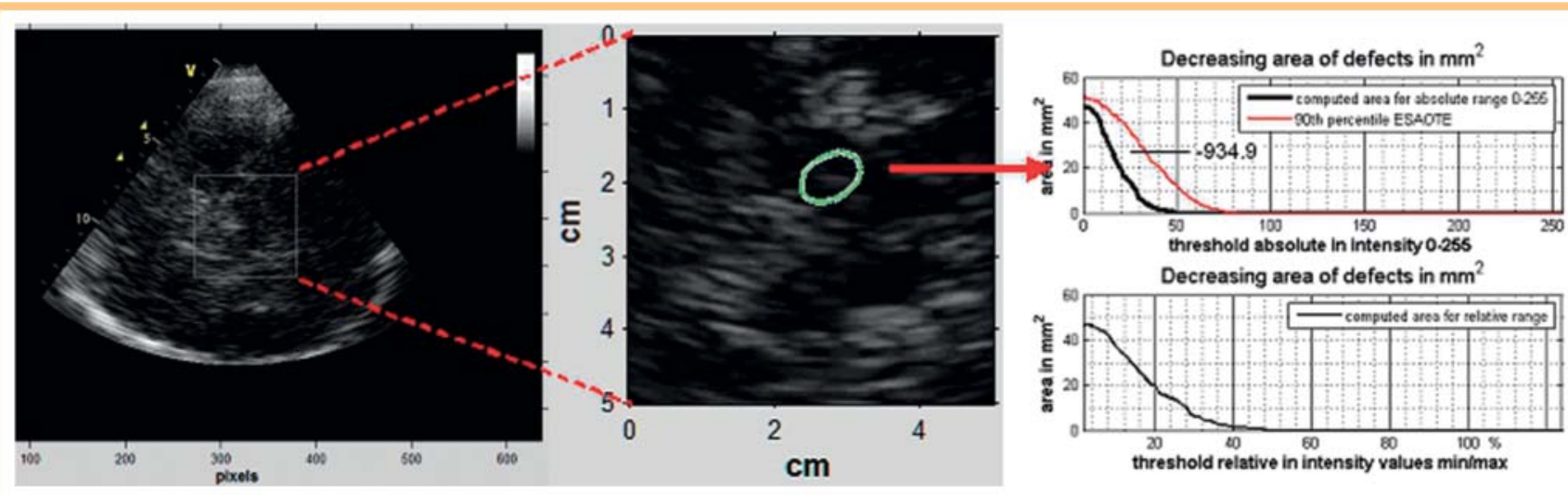

Fig. 6 Example of automated detection of the mesencephalon (window $50 \times 50 \mathrm{~mm}$ ) within an axial sonogram of the brain at midbrain level using MATLAB-based software [12]. For automated measurement of substantia nigra echogenicity, the elliptical marker indicating the region of interest (ROI) with a size of $50 \mathrm{~mm}^{2}$ was placed manually in the anatomical region of substantia nigra. The automated calculation of the difference between the 90th percentile cut-off value obtained from measures in normal population and the counted value in this healthy individual proved normal echogenicity of substantia nigra.
Abb. 6 Beispiel für eine automatisierte Erkennung des Mesenzephalons (Fenstergröße $50 \times 50 \mathrm{~mm}$ ) innerhalb eines axialen Sonogramms des Gehirns auf Mittelhirn-Höhe mittels einer MATLAB-basierten Software [12]. Für die automatisierte Messung der Substantia-nigra-Echogenität wurde der elliptische Marker der „Region of interest“ (ROI) mit einer Größe von $50 \mathrm{~mm}^{2}$ manuell in die anatomische Region der Substantia nigra platziert. Die automatische Berechnung der Differenz zwischen der $90 \%$-Perzentile, erhalten aus Referenzmessungen in der Normalpopulation, und dem hier bestimmten Messwert ergab eine normale Echogenität der Substantia nigra im hier untersuchten Individuum. 
by an electromagnetic system, composed of a transmitter and a small receiver, mounted on the transducer [50]. Pilot studies demonstrated a very high accuracy of fusion images, with an average cranio-caudal error of 0.5 (range, $0-0.7$ ) $\mathrm{cm}$ and an average lateral shift of $0.1(0-0.5) \mathrm{cm}$ [50]. The mean time for the complete TCS examination including the fusion imaging procedure did not exceed 40 minutes. An interesting clinical application in movement disorder patients with DBS is the control of intracranial lead tip position which can be documented by the fusion of post-implantation TCS images with preoperative MRI (๑ Fig. 3).

All these new technologies, i.e., automated structure detection, digitized image analysis, and fusion imaging, promise a more reliable detection of brain pathologies on TCS in the future, even of brain structures that are hardly assessable visually due to their isoechogenicity to the surrounding parenchyma. This might even enable the detection of subtle changes of echogenicity over time in distinct brain structures as a correlate of disease progression.

\section{Concluding remarks \\ $\nabla$}

TCS can currently be recommended in clinical practice for the assessment of ventricle widths (especially the $3^{\text {rd }}$ ventricle), the early and differential diagnosis of $\mathrm{PD}$, and the post-operative position control of DBS electrodes. High intra- and interrater reliability and diagnostic accuracy of planimetric SN echogenicity measurements have been demonstrated by numerous groups (for review, see [8]) which is a clear progress compared to the previous review published here in 2006 [51]. The following factors impair the reliability of SN TCS and need to be excluded before diagnostic application [8]:

1. the inadequate qualification of the investigator,

2. the missing initial instruction and supervision of the investigator by another expert experienced in TCS in movement disorders,

3. the use of a US-S not specifically engineered and adapted for TCS,

4. inappropriate, or changing US-S settings,

5. the missing establishment of normal ranges of SN echogenic sizes in the referring ultrasound lab by investigation of at least 50 healthy subjects,

6. the variable, erroneous inclusion of highly echogenic signals of structures neighboring the SN such as the red nucleus and structures of the basal cisterns.

After excluding these sources of error, SN TCS can be learned by a physician within $2-8$ weeks depending on her/his previous ultrasound experience, and is reliably performed even by adequately trained doctoral students and medical technicians [1, 8]. However, the ability of reliably assessing the midbrain raphe, basal ganglia and other structures still requires more experience and supervision, at least for several months. Still, for scientific publications only TCS data should be used that were obtained by investigators who had performed and analyzed images of at least 200 patients under qualified supervision [8]. The upcoming digitized analysis and fusion imaging technologies promise a more investigator-independent assessment of deep brain structures in the near future.

\section{References}

1 Berg $D$, Godau J, Walter $U$. Transcranial sonography in movement disorders. Lancet Neurol 2008; 7: 1044-1055
2 Walter U, Behnke S, Eyding J et al. Transcranial brain parenchyma sonography in movement disorders: state of the art. Ultrasound Med Biol 2007; 33: $15-25$

3 Go CL, Frenzel A, Rosales RL et al. Assessment of substantia nigra echogenicity in German and Filipino populations using a portable ultrasound system. J Ultrasound Med 2012; 31: 191-196

4 Walter U, Kanowski M, Kaufmann J et al. Contemporary ultrasound systems allow high-resolution transcranial imaging of small echogenic deep intracranial structures similarly as MRI: a phantom study. Neuroimage 2008; 40: $551-558$

5 Kern R, Perren F, Kreisel $S$ et al. Multiplanar transcranial ultrasound imaging: standards, landmarks and correlation with magnetic resonance imaging. Ultrasound Med Biol 2005; 31: 311 - 315

6 Skoloudík D, Walter $U$. Method and validity of transcranial sonography in movement disorders. Int Rev Neurobiol 2010; 90: 7-34

7 Walter $U$, Kirsch M, Wittstock $M$ et al. Transcranial sonographic localization of deep brain stimulation electrodes is safe, reliable and predicts clinical outcome. Ultrasound Med Biol 2011; 37: $1382-1391$

8 Walter $U$. How to measure substantia nigra hyperechogenicity in Parkinson's disease: detailed guide with video. J Ultrasound Med 2013; 32: $1837-1843$

9 Školoudík D, Fadrná T, Bártová P et al. Reproducibility of sonographic measurement of the substantia nigra. Ultrasound Med Biol 2007; 33: $1347-1352$

10 van de Loo S, Walter $U$, Behnke $S$ et al. Reproducibility and diagnostic accuracy of substantia nigra sonography for the diagnosis of Parkinson's disease. J Neurol Neurosurg Psychiatry 2010; 81: 1087-1092

11 Plate A, Ahmadi SA, Pauly 0 et al. Three-dimensional sonographic examination of the midbrain for computer-aided diagnosis of movement disorders. Ultrasound Med Biol 2012; 38: 2041 - 2050

12 Blahuta J, Soukup T, Čermák P et al. Ultrasound medical image recognition with artificial intelligence for Parkinson's disease classification. In: Biljanovic P, Butkovic Z, Skala K et al. (eds.) Proceedings of 35th International Convention on Information and Communication Technology, Electronics and Microelectronics Rijeka: Croatian Society for Information and Communication Technology, Electronics and Microelectronics - MIPRO; 2012: 958 -962

13 Chen L, Hagenah J, Mertins A. Feature analysis for Parkinson's disease detection based on transcranial sonography image. Med Image Comput Comput Assist Interv 2012; 15: 272 - 279

14 Walter $U$. Transcranial sonography in brain disorders with trace metal accumulation. Int Rev Neurobiol 2010; 90: 166-178

15 Berg D, Godau J, Riederer P et al. Microglia activation is related to substantia nigra echogenicity. J Neural Transm 2010; 117: 1287 - 1292

16 Berg D, Becker G, Zeiler B et al. Vulnerability of the nigrostriatal system as detected by transcranial ultrasound. Neurology 1999; 53: $1026-$ 1031

17 Mehnert S, Reuter I, Schepp K et al. Transcranial sonography for diagnosis of Parkinson's disease. BMC Neurol 2010; 10: 9

18 Hagenah J, König IR, Sperner J et al. Life-long increase of substantia nigra hyperechogenicity in transcranial sonography. Neuroimage 2010; 51: $28-32$

19 Behnke S, Double KL, Duma S et al. Substantia nigra echomorphology in the healthy very old: Correlation with motor slowing. Neuroimage 2007; 34: 1054-1059

20 Mijajlović $M$, Dragasević $N$, Stefanova E et al. Transcranial sonography in spinocerebellar ataxia type 2. J Neurol 2008; 255: 1164-1167

21 Stockner $H$, Sojer M, Seppi K et al. Midbrain sonography in patients with essential tremor. Mov Disord 2007; 22: 414-417

22 Fedotova EIu, Chechetkin AO, Shadrina MI et al. Transcranial sonography in Parkinson's disease. Zh Nevrol Psikhiatr Im S S Korsakova 2011; 111: 49-55

23 Kim JY, Kim ST, Jeon SH et al. Midbrain transcranial sonography in Korean patients with Parkinson's disease. Mov Disord 2007; 22: 1922 1926

24 Glaser $M$, Weber $U$, Hinrichs $H$ et al. Transkranielle Sonographie des Mittelhirns mit verschiedenen Ultraschallsystemen. Klin Neurophysiol 2006; 37: $165-168$

25 Vivo-Orti MN, Tembl JI, Sastre-Bataller I et al. Evaluación de la sustancia negra mediante ultrasonografía transcraneal. Rev Neurol 2013; 56: $268-274$

26 Becker G, Becker T, Struck M et al. Reduced echogenicity of brainstem raphe specific to unipolar depression: a transcranial color-coded realtime sonography study. Biol Psychiatry 1995; 38: 180-184 
27 Berg D, Behnke S, Seppi K et al. Enlarged hyperechogenic substantia nigra as a risk marker for Parkinson's disease. Mov Disord 2013; 28: 216-219

28 Walter $U$. Substantia nigra hyperechogenicity is a risk marker of Parkinson's disease: no. J Neural Transm 2011; 118: 607-612

29 Doepp F, Plotkin M, Siegel L et al. Brain parenchyma sonography and 123I-FP-CIT SPECT in Parkinson's disease and essential tremor. Mov Disord 2008; 23: 405-410

30 Behnke S, Berg D, Naumann M et al. Differentiation of Parkinson's disease and atypical parkinsonian syndromes by transcranial ultrasound. J Neurol Neurosurg Psychiatry 2005; 76: $423-425$

31 Walter $U$, Dressler $D$, Probst T et al. Transcranial brain sonography findings in discriminating between parkinsonism and idiopathic Parkinson disease. Arch Neurol 2007; 64: 1635 - 1640

32 Busse K, Heilmann R, Kleinschmidt S et al. Value of combined midbrain sonography, olfactory and motor function assessment in the differential diagnosis of early Parkinson's disease. J Neurol Neurosurg Psychiatry 2012; 83: $441-447$

33 Berardelli A, Wenning GK, Antonini A et al. EFNS/MDS-ES recommendations for the diagnosis of Parkinson's disease. Eur J Neurol 2013; 20: $16-34$

34 Schmidauer C, Sojer M, Seppi K et al. Transcranial ultrasound shows nigral hypoechogenicity in restless legs syndrome. Ann Neurol 2005; 58: 630-634

35 Godau J, Schweitzer KJ, Liepelt I et al. Substantia nigra hypoechogenicity: definition and findings in restless legs syndrome. Mov Disord 2007; 22: $187-192$

36 Walter U, Hoeppner J, Prudente-Morrissey L et al. Parkinson's diseaselike midbrain sonography abnormalities are frequent in depressive disorders. Brain 2007; 130: 1799-1807

37 Berg D, Supprian T, Hofmann E et al. Depression in Parkinson's disease: brainstem midline alteration on transcranial sonography and magnetic resonance imaging. J Neurol 1999; 246: 1186-1193

38 Krogias C, Strassburger K, Eyding $J$ et al. Depression in patients with Huntington disease correlates with alterations of the brain stem raphe depicted by transcranial sonography. J Psychiatry Neurosci 2011; 36: $187-194$

39 Postert T, Eyding J, Berg $D$ et al. Transcranial sonography in spinocerebellar ataxia type 3. J Neural Transm Suppl 2004; 68: 123-133
40 Synofzik M, Godau J, Lindig $T$ et al. Transcranial sonography reveals cerebellar, nigral, and forebrain abnormalities in Friedreich's ataxia. Neurodegener Dis 2011; 8: 470-475

41 Naumann M, Becker G, Toyka KV et al. Lenticular nucleus lesion in idiopathic dystonia detected by transcranial sonography. Neurology 1996; 47: $1284-1290$

42 Walter $U$, Blitzer A, Benecke $R$ et al. Sonographic detection of basal ganglia abnormalities in spasmodic dysphonia. Eur J Neurol 2014; 21: $349-352$

43 Wollenweber FA, Schomburg R, Probst $M$ et al. Width of the third ventricle assessed by transcranial sonography can monitor brain atrophy in a time- and cost-effective manner - results from a longitudinal study on 500 subjects. Psychiatry Res 2011; 191: 212 - 216

44 Hagenah J, König IR, Kötter C et al. Basal ganglia hyperechogenicity does not distinguish between patients with primary dystonia and healthy individuals. J Neurol 2011; 258: 590-595

45 Brüggemann N, Schneider SA, Sander T et al. Distinct basal ganglia hyperechogenicity in idiopathic basal ganglia calcification. Mov Disord 2010; 25: 2661 - 2664

46 Blahuta J, Soukup T, Čermák P. The image recognition of brain-stem ultrasound images with neural network based on PCA. In: Savino M, Andria G (eds.) 2011 IEEE International Symposium on Medical Measurements and Applications (MeMeA 2011) Proceedings Bari: IEEE; 2011: $134-142$

47 Sakalauskas A, Lukoševičius A, Laučkaité K et al. Automated segmentation of transcranial sonographic images in the diagnostics of Parkinson's disease. Ultrasonics 2013; 53: 111-121

48 Pauly O, Ahmadi SA, Plate A et al. Detection of substantia nigra echogenicities in 3D transcranial ultrasound for early diagnosis of Parkinson disease. Med Image Comput Comput Assist Interv 2012; 15: $443-450$

49 Skoloudik D, Herzig R, Blahuta J et al. Comparison of automatic and manual transcranial sonographic morphometric measurement of the substantia nigra. Neurology 2013; 80 (Meeting Abstracts 1): S39.006

50 Forzoni L, D'Onofrio S, De Beni S et al. Virtual Navigator Registration Procedure for Transcranial Application. In: Hellmich C, Hamza MH, Simsik D (eds.) Proceedings of the IASTED International Conference Biomedical Engineering (BioMed 2012). February 15-17, 2012 Innsbruck Austria Calgary: ACTA Press; 2012: 496-503

51 Berg D, Behnke S, Walter U. Application of transcranial sonography in extrapyramidal disorders: updated recommendations. Ultraschall in Med 2006; 27: $12-19$ 